\title{
Bacteriological Profile of Burn Patients and Antimicrobial Susceptibility Pattern of their Wound Isolates at Nepal Cleft and Burn Center
}

\author{
Apar Lamichhane, ${ }^{1}$ Kiran Kishor Nakarmi, ${ }^{2}$ Peeyush Dahal, ${ }^{1}$ Surendra Jung Basnet, ${ }^{2}$ Pashupati \\ Babu Pokharel, ${ }^{1}$ Suraj Bhattarai, ${ }^{3}$ Shankar Man Rai ${ }^{2}$ \\ ${ }^{1}$ Department of Bums and Plastic Surgery National Academy of Medical Sciences (NAMS), Kathmandu, Nepal. \\ ${ }^{2}$ Department of Burns, Plastic and Reconstructive Surgery, Kirtipur Hospital, Kirtipur, Nepal. ${ }^{3}$ Global Institute for \\ Interdisciplina ry Studies, Kathmandu, Nepal.
}

\begin{abstract}
Background: Burn infections are the major causes of morbidity and mortality in burn patients. The infectious agent could be both Gram positive and Gram negative bacteria. The aim of this research was to study the bacteriological profile of burn patients and anti-microbial susceptibility pattern of their wound isolates. Methods: This prospective observational study was conducted in Kirtipur Hospital, Nepal from January $1^{\text {st }}$ to March $31^{\text {st }} 2019$. A total of 109 burn patients were included and their wound swabs were collected at the time of admission. All isolates were identified by standardized microbiological procedures. Anti-microbial susceptibility tests were performed by Kirby Bauer disc diffusion method. Results: Of 109 burn wound samples, $56(59 \%)$ yielded culture growth and the Gram negative isolates were more common than Gram positives $(77 \%$ vs. $23 \%)$. The most common organism isolated was Klebsiella spp. (25\%) followed by Acinetobacter spp. (21\%) and Staphylococcus aureus (18\%). Most burn wound isolates were of resistant strain. Particularly, highly resistant strain of Acinetobacter spp. were isolated, most of which were sensitive to tigecycline, polymyxin B and colistin only. Conclusion: Gram negative isolates were common in burn wound isolates and the antibiotic susceptibility pattern was different for different organisms. The use of antimicrobials should be judicious to further not escalate the problem of antimicrobial resistance in the healthcare settings.
\end{abstract}

Keywords: antimicrobial susceptibility; burn infection; bacteriological profile.

\section{INTRODUCTION}

Infection is the major cause of morbidity and mortality in burn patients who are hospitalized. ${ }^{1}$ There is an estimation that $75 \%$ of the mortality associated with burn injuries is related to sepsis in developing countries. ${ }^{2}$ Burn injury leads to a state of immune system dysfunction that predisposes patients to infection which is aided by the loss of the natural skin barrier. ${ }^{3}$ There is interplay of pro and anti-inflammatory signals that result in dysregulation off the innate and adaptive immune responses. ${ }^{4}$ After a burn injury there is a massive release of humoral factors, including cytokines, prostaglandins, vasoactive prostanoids and leukotrienes. ${ }^{5}$ The neutrophils have a decreased chemotaxis and bactericidal activity. ${ }^{6}$ There is less phagocytic activity and lymphokine production by macrophages. Natural killer cells activity are diminished $^{7}$. It is due to presence of high amount of dead cells. ${ }^{8}$ As foreign bodies and dead cell are abundant in burnt areas the macrophages reach there and pus will develop as an end result. ${ }^{8}$ The reason for this is due to secondary immunodeficiency. ${ }^{8}$ With the decrease in immune system, burns provide a suitable site for bacterial multiplication and are rich sources of infection because the dead cells provide nutrients to extremophiles. $^{9}$

There are various organisms that are isolated from burn wound. ${ }^{10}$ Aerobic bacterial isolates from burn wounds include Gram positive organisms like Staphylococcus aureus, coagulase negative Staphylococci and Enterococcus spp; similarly Gram negative organisms like Pseudomonas aeruginosa, Escherichia coli, Klebsiella pneumoniae, Serratia marcescens, Enterobacter spp, Proteus spp and Acinetobacter spp are isolated. ${ }^{11}$ The incidence of less common microbes is increasing, as multidrug-resistant strains of the more common isolates. ${ }^{9}$ Polyantibiotic resistance has been noted in Gram positive organisms like methicillin-resistant Staphylococcus aureus (MRSA), and also in Gram negative bacilli like $P$. aeruginosa and Acinetobacter spp. ${ }^{12}$ The nature of microbial colonization of the wound, flora changes, and antimicrobial sensitivity profiles should be taken into consideration in using empirical antimicrobial therapy for burn patients. ${ }^{13}$ Periodical culturing and surveillance is very important potential microorganisms and their

Correspondence: Dr. Apar Lamichhane, Department of Bums and Plastic Surgery National Academy of Medical Sciences (NAMS), Kathmandu, Nepal. Email: aparlamichhane@gmail.com. Phone: +977-9856039275. Article received: 2019-02-09. Article accepted:2019-05-22. 
sensitivity/susceptibility pattern will prompt early management and possible decrease in morbidity and mortality of burn patients from sepsis. The present study aims to find out the common microflora in wounds of the burn patients at Kirtipur Hospital, Nepal. This study will help to assess the bio-burden of infections at the center and antimicrobial susceptibility testing will help to formulate antibiotic policy for better management of these patients.

\section{METHODS}

This study was prospective observational study done after approval from the Institutional Review Board (IRB) of NAMS (National Academy of Medical Sciences) between January $1^{\text {st }}-$ March $31^{\text {st. }}$; 2018. Patients who did not fall in the exclusion criteria were included in the study. Exclusion criteria being patient or patient party who refuse to enroll in the study. At the time of admission sterile cotton swabs were smoothly rolled over the burn wound area aseptically. ${ }^{14}$ The swabs were transported to the bacteriology laboratory in sterile test tubes and inoculated on MacConkey agar media (HiMedia Laboratories Pvt. Ltd., Mumbai) and blood agar media (HiMedia Laboratories Pvt. Ltd., Mumbai). Aerobic incubation was done at $37^{\circ}$ C for 24 hours. ${ }^{15}$ The media showing no colony, were noted down as no growth. The media, with colonies, were processed following the standard bacteriological procedures Gram-staining was done from the colonies. Identification of bacterial isolates were done by conventional biochemical tests. ${ }^{15}$

Antimicrobial susceptibility testing of the bacterial isolates was done by disk diffusion technique (using Kirby Bauer's method) ${ }^{16}$ on Mueller-Hinton agar (MHA) (HiMedia Laboratories Pvt. Ltd., Mumbai) as per Clinical and Laboratory Standards Institute (CLSI) guidelines. ${ }^{15}$ Inoculum for individual isolate was made by direct colony suspension in nutrient broth. The turbidity of the broth was adjusted to a 0.5 McFarland standard suspension. ${ }^{15}$ The drugs listed in British pharmacopeia and commonly used in the center were used. ${ }^{17}$ The MHA plates were inoculated and then incubated for 24 hours at $37^{\circ} \mathrm{C}$. The MHA plates were examined, the zone of inhibition was noted and the sensitivity pattern of the bacterial isolates to various antibiotics were detected as per CLSI guideline. ${ }^{15}$ As a control, antibiotic susceptibility test of ATCC (American Type Culture Collection) 25923 ( $S$. aures) and ATCC 25922 (E.coli) were performed. ${ }^{18}$

Statistical Package For The Social Sciences (SPSS) version 21 was used for data entry and analysis. The sensitivity and resistance of different organism isolated to the drugs were expressed in terms of percentage. $p$ value of less than 0.05 was considered significant. Quality control and verification of data were done as follows : A sample was triplicated and repeated two times in a interval of two weeks. Purity plating was performed for the media and equipments were calibrated. ${ }^{19}$ Open Epi software version-2 was used to calculate the sample size.

$$
\frac{(z \text {-Score })^{2} \times \text { Standard deviation } \times(1-\text { Standard Deviation })}{\text { margin of error }{ }^{2}}
$$

For our study for confidence Level of $95 \%$ the $\mathrm{Z}$ score $=1.9$ Standard deviation $=0.5$ Margin of Error $=10 \%$

Sample size $=(1.96)^{2} \times 0.5 \times(1-0.5) /(0.1)^{2}=96.04$ with 10 percent drop outs for $96=10$

Total Sample size $=$ Sample size $+10(10$ percent drop outs of 96) $=106$

\section{RESULTS}

Burn wound swabs were collected from 109 patients during admission. Of them $36(33 \%)$ samples were from male and $73(67 \%)$ were from female. Most of the patient were between 21-30 years' age group twenty-three followed by $0-10$ years' age group twenty (Figure 1).

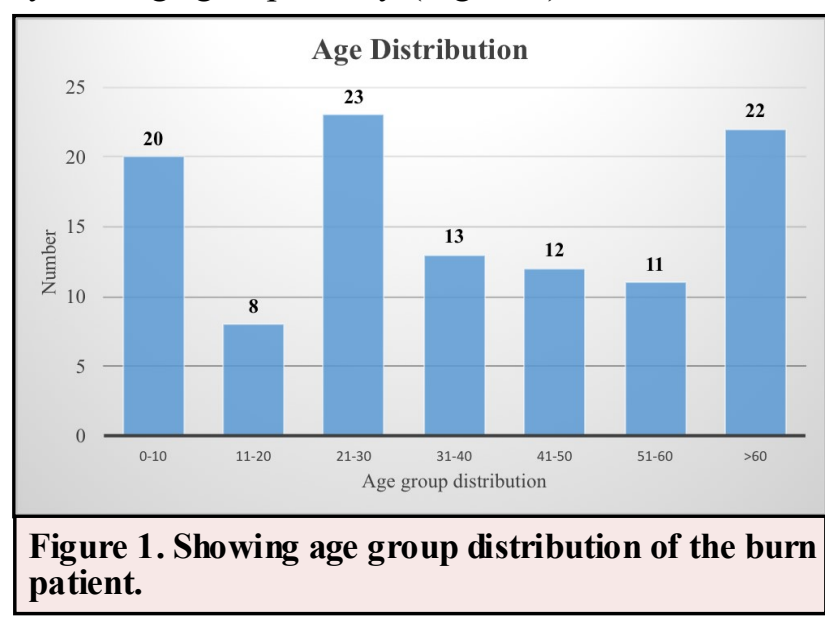

There was variation in the Total body surface area (TBSA) burn between the groups and most patient were between 11-20 \% TBSA group thirtyone.Followed by 1-10\% TBSA group twenty nine and $21-30 \%$ TBSA group twenty-four. The least was $41-50 \%$ TBSA group four (Figure 2).

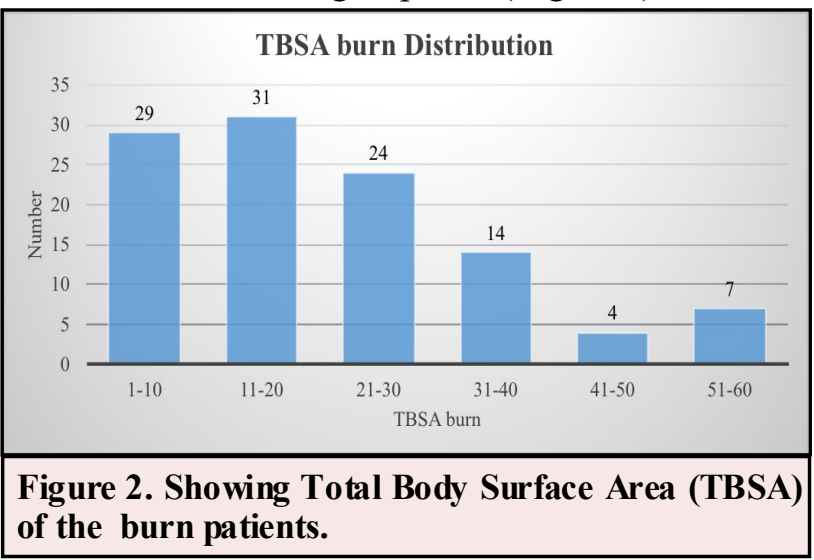

Of the total sample that were collected during the time of admission 53 samples showed no growth 
for aerobic bacterial culture and 56 sample showed growth for aerobic bacterial culture. Among the swab sample of the patient who showed no growth to aerobic bacterial culture the average days to admission to our center was 1.61 days and who showed growth to aerobic bacterial culture it was 5.57 days (Figure 3 ).

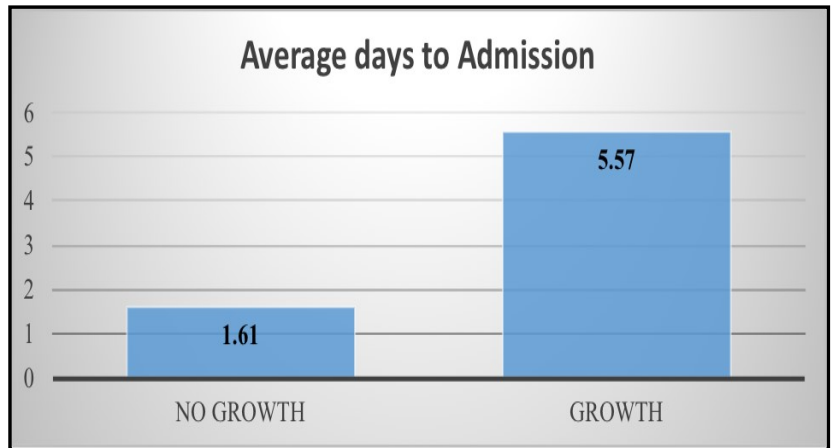

Figure 3. Showing average days to hospital in growth and no growth sample.

Of the total positive samples thirteen (23\%) were Gram positive and forty-three $(77 \%)$ were Gram negative. The most common organism isolated was Klebsiella spp fourteen (25\%), Acinetobacter spp twelve (21\%), Staphylococcus spp. ten (18\%), Pseudomonas spp. six (11\%), Citrobacter spp. five (9\%), E.coli four (7\%), Enterococcus spp. three (5\%) and Proteus spp. two (4\%) (Figure 4).

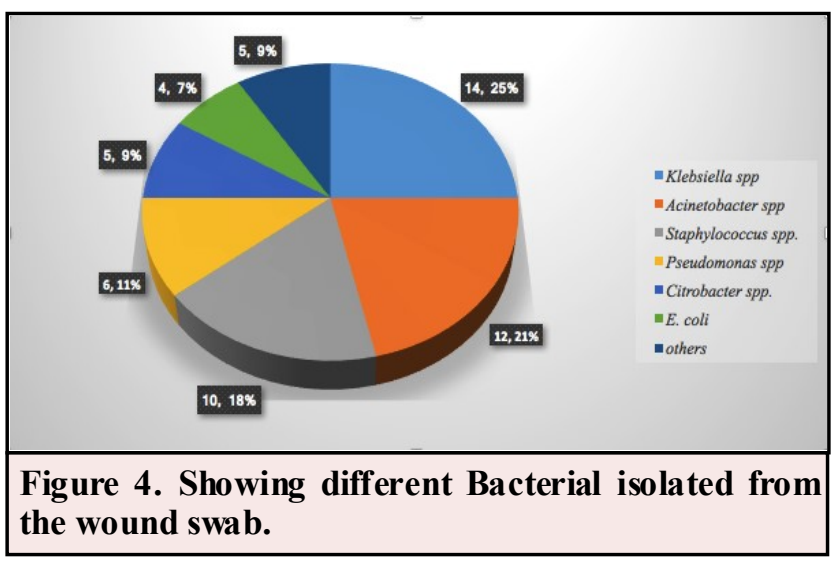

Among the Gram positives, Staphylococcus spp. were sensitive to teicoplanin $90 \%$, tetracycline hydrochloride $80 \%$, ceftriaxone sodium $70 \%$ and were less sensitive to cloxacillin sodium $50 \%$, amoxicillin trihydrate and trimethoprim+suphamethoxazole $30 \%$. Enterococcus spp. were $100 \%$ sensitive to ceftriaxone sodium, trimethoprim+ sulphamethoxazole, cefeperazone+ sulbactam, ciprofloxacin, vancomycin hydrochloride. However, they were less sensitive to gentamicin sulfate $66.66 \%$ and tetracycline hydrochloride $50 \%$ (Table $1)$.

Among the Gram negative, Klebsiella spp showed no sensitivity to common drugs like amoxicillin

\begin{tabular}{|c|c|c|}
\hline \multicolumn{3}{|c|}{$\begin{array}{l}\text { Table 1. Antimicrobial Susceptibility pattern of } \\
\text { Gram positive isolates in burn patients. }\end{array}$} \\
\hline & $\begin{array}{l}\text { Staphylococcus } \\
\text { spp. } \\
\text { Sensitivity (\%) }\end{array}$ & $\begin{array}{l}\text { Enterococcus } \\
\text { spp. Sensitiv- } \\
\text { ity }(\%)\end{array}$ \\
\hline amikacin sulfate & $60 \%$ & $100 \%$ \\
\hline amoxicillin trihydrate & $30 \%$ & $100 \%$ \\
\hline cephlexin & $50 \%$ & ND \\
\hline $\begin{array}{l}\text { cefepera- } \\
\text { zone+sulbactam }\end{array}$ & ND & $100 \%$ \\
\hline ceftriaxone sodium & $70 \%$ & $100 \%$ \\
\hline ciprofloxacin & ND & $100 \%$ \\
\hline chloramphenicol & $60 \%$ & ND \\
\hline cloxacillin & $50 \%$ & ND \\
\hline $\begin{array}{l}\text { trimethoprim+ sulpha- } \\
\text { methoxazole }\end{array}$ & $30 \%$ & $100 \%$ \\
\hline gentamicin sulfate & $40 \%$ & 66.66 \\
\hline levofloxacin & ND & $100 \%$ \\
\hline teicoplanin & $90 \%$ & ND \\
\hline $\begin{array}{l}\text { tetracycline hydrochlo- } \\
\text { ride }\end{array}$ & $80 \%$ & $50 \%$ \\
\hline $\begin{array}{l}\text { vancomycin hydro- } \\
\text { chloride }\end{array}$ & ND & $100 \%$ \\
\hline
\end{tabular}

trihydrate, ceftazidime, doxycycline and meropenem. They showed very less sensitivity to amikacin (35.71\%), cefepime (14.28\%), cefeperazone+Sulbactam (44.44\%), ceftriaxone $(14.28 \%)$, trimethoprim+sulfamethoxazole $(35.71 \%)$, gentamicin (30.76\%), levofloxacin $(35.71 \%)$. They showed good sensitivity to tigecycline (88.88\%) and $100 \%$ to colsitin sulphate and polymyxin B. Acinetobacter spp. showed no sensitivity to amoxicillin, amikacin, amoxicillin + clauvanic acid and ceftazidime. They showed very less sensitivity to cefepime (16.67\%), cefeperazone+sulbactam $(58.33 \%), \quad$ ceftriaxone $(8.33 \%), \quad$ ciprofloxacin $\quad(16.67 \%)$, trimethoprim+sulfamethoxazole $\quad(8.33 \%)$, doxycilline (41.66\%), gentamicin (25\%), imipenem $(33.33 \%)$, levofloxacin (33.33\%), meropenem $(33.33 \%)$, piperacillin+tazobactam $(33.33 \%)$. They showed good sensitivity to tigecycline $83.33 \%$ and $100 \%$ sensitivity to colsitin sulphate and polymyxin B. Pseudomonas Spp. showed no sensitivity to cefeperazone+sulbactam, doxycycline. They showed very less sensitivity to amikacin $(50 \%)$, cefepime $(33.33 \%)$, ciprofloxacin $(50 \%)$, gentamicin (20\%), imipenem (50\%), levofloxacin (50\%), meropenem (50\%), piperacillin+tazobactam (33.33\%), teicoplanin (25\%) and $100 \%$ sensitivity to colsitin sulphate and polymyxin B. Citrobacter Spp. showed no sensitivity to amoxicillin. They showed less sensitivity to cefepime $(60 \%)$, cefeperazone + sulbactam $(60 \%)$, cefotaxim $(60 \%)$, ceftazidime $(40 \%)$, ceftriaxone $(60 \%)$, ciprofloxacin $(60 \%)$, cotrimoxazole $20 \%$, doxycilline $(60 \%)$. They showed good sensitivity to amikacin $(80 \%)$, gentamicin $(80 \%)$, imipenem $(66.66 \%)$, meropenem $(66.66 \%)$ and tazobactam+piperacillin $(66.66 \%)$ and $100 \%$ sensitivity to colsitin sulphate and polymyxin B. E.coli showed no sensitivity to amoxicillin, amoxicillin+clauvanic acid and 
doxycycline. They showed less sensitivity cefotaxime $(25 \%)$, ceftazidime $(25 \%)$, ceftriaxone (25\%), gentamicin $(50 \%)$, and more sensitivity to amikacin $(75 \%)$, cefeperazone+sulbactam $(75 \%)$, ciprofloxacin $(75 \%)$, imipenem $(75 \%)$, levofloxacin $(75 \%)$ and meropenem $(75 \%)$ and showed $100 \%$ sensitivity to colistin Sulphate, polymyxin B and tigecycline. Proteus spp. showed no sensitivity to amoxicillin and trimethoprim+sulphamethoxazole. They showed less sensitivity to amoxicillin+clauvanic acid $(50 \%)$ cefeperazone+sulbactam $\quad(50 \%)$, ciprofloxacin $(50 \%)$, gentamicin $(50 \%)$, levofloxacin (50\%) and showed $100 \%$ sensitivity to amikacin, ceftazidime, imipenem, meropenem, piperacillin+tazobactam (Table 2).

\section{DISCUSSIONS}

is similar to our previous published data by Karki et al $(2018)^{23}$ who found that $0-20 \%$ group had the highest number of patient and by Rai et al $(2014)^{24}$ who also found $0-20 \%$ group had the highest number of patient.

In our study we found out that $53(49 \%)$ wound swab culture samples showed no aerobic bacterial growth and 56 (51\%) showed growth of aerobic bacteria. This was obvious because this was the analysis of the swab that were taken during the time of admission and most of the time it will show no growth until the organism has colonized and the average day to admission of those patient whose swab showed no growth was 1.61 days and whose showed growth was 5.57 days. Which was statistically significant $p$ value

\begin{tabular}{|c|c|c|c|c|c|c|}
\hline & $\begin{array}{l}\text { Klebsiella } \\
\text { spp. Sensi- } \\
\text { tivity (\%) }\end{array}$ & $\begin{array}{l}\text { Acinetobac- } \\
\text { terspp. Sensi- } \\
\text { tivity }(\%)\end{array}$ & $\begin{array}{l}\text { Pseudomonas } \\
\text { spp. } \\
\text { Sensitivity(\%) }\end{array}$ & $\begin{array}{l}\text { Citrobacter } \\
\text { spp. } \\
\text { Sensitivity(\%) }\end{array}$ & $\begin{array}{l}\text { E. coli } \\
\text { Sensitiv- } \\
\text { ity }(\%)\end{array}$ & $\begin{array}{l}\text { Proteus spp } \\
\text { Sensitivity } \\
(\%)\end{array}$ \\
\hline amikacin sulfate & $35.71 \%$ & $0 \%$ & $50 \%$ & $80 \%$ & $75 \%$ & $100 \%$ \\
\hline amoxicillin trihydrate & $0 \%$ & $0 \%$ & ND & $0 \%$ & $0 \%$ & $0 \%$ \\
\hline amoxicillin+ clauvanic acid & ND & $0 \%$ & ND & ND & $0 \%$ & $50 \%$ \\
\hline Cefepime & $14.28 \%$ & $16.67 \%$ & $33.33 \%$ & $60 \%$ & ND & ND \\
\hline cefeperazone + sulbactam & $44.44 \%$ & $58.33 \%$ & $0 \%$ & $60 \%$ & $75 \%$ & $50 \%$ \\
\hline Cefotaxime & ND & $8.33 \%$ & ND & $60 \%$ & $25 \%$ & ND \\
\hline Ceftazidime & $0 \%$ & $0 \%$ & $80 \%$ & $40 \%$ & $25 \%$ & $100 \%$ \\
\hline ceftriaxone sodium & $14.28 \%$ & $8.33 \%$ & ND & $60 \%$ & $25 \%$ & $50 \%$ \\
\hline Ciprofloxacin & $50 \%$ & $16.67 \%$ & $50 \%$ & $60 \%$ & $75 \%$ & $50 \%$ \\
\hline colistin sulphate & $100 \%$ & $100 \%$ & $100 \%$ & $100 \%$ & $100 \%$ & ND \\
\hline trimethoprim+sulphamethoxazole & $35.71 \%$ & $8.33 \%$ & ND & $20 \%$ & $25 \%$ & $0 \%$ \\
\hline doxycycline hyclate & $0 \%$ & $41.66 \%$ & $0 \%$ & $60 \%$ & $0 \%$ & ND \\
\hline gentamicin sulfate & $30.76 \%$ & $25 \%$ & $20 \%$ & $80 \%$ & $50 \%$ & $50 \%$ \\
\hline imipenem & $10 \%$ & $33.33 \%$ & $50 \%$ & $66.66 \%$ & $75 \%$ & $100 \%$ \\
\hline levofloxacin & $35.71 \%$ & $33.33 \%$ & $50 \%$ & $80 \%$ & $75 \%$ & $50 \%$ \\
\hline Meropenem & $0 \%$ & $33.33 \%)$ & $50 \%$ & $66.66 \%$ & $75 \%$ & $100 \%$ \\
\hline piperacillin+tazobactam & $10 \%$ & $33.33 \%$ & $33.33 \%$ & $66.66 \%$ & ND & $100 \%$ \\
\hline polymxin-B & $100 \%$ & $100 \%$ & $100 \%$ & $100 \%$ & $100 \%$ & ND \\
\hline Teicoplanin & ND & ND & $25 \%$ & ND & ND & ND \\
\hline Tigecycline & $88.88 \%$ & $83.33 \%$ & ND & $100 \%$ & $100 \%$ & ND \\
\hline
\end{tabular}

ND: Not done

In our study we found out that the incidence of burn injury was more in females. This finding is in accordance to a study done by Paudel and Dahal $(2010)^{20}$ previously at Bir Hospital in Nepal females $(55 \%)$ were more affected than males (45\%). According to WHO (World Health

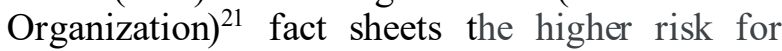
females is associated with open fire cooking, or inherently unsafe cook stoves, which can ignite loose clothing. Open flames used for heating and lighting also pose risks, and self-directed or interpersonal violence are also factors. But this data is true only for low and low middle income country for high income country it is the males who are more affected. A systematic review done by Smolle et al $(2017)^{22}$ which included the data mostly of high income countries found the mean male:female ratio of all studies together was 1.92:1. The TBSA(Total Body Surface Area) burn group were mostly between 0 and $20 \%$. This result less than 0.05 .

In our study we found Gram positive isolates from the wound swab were less than Gram negative isolates. The possible explanation could be the average day to hospital admission in positive culture was 5.57 days and by the end of the week Gram negative organism are more common than Gram positive. This is consistent with the previous study done by Mundhada et al $(2015)^{25}$ who found that Gram negative isolates were 3 times more common than Gram positive. Similarly, Aljanaby et al $(2018)^{26}$ found $34.7 \%$ of the isolates to be Gram positive and $66.3 \%$ of the isolates to be Gram negative. Chamania et al $(2012)^{27}$ found Gram positive sample to be $25 \%$ and Gram negative to be $75 \%$ in burn wound culture.

In our study the most common aerobic bacterial 
organism isolated from the wound swab was Klebsiella spp. (25\%) followed by Acinetobacter spp. (21\%), Staphylococcus spp.(18\%), Pseudomonas Spp. (11\%), Citrobacter Spp. (9\%), E.coli (7\%), Enterococcus Spp. (5\%),Proteus Spp. (4\%). A Similarly study by Al-Aali $(2016)^{28}$ revealed Staphylococcus aureus, Klebsiella spp. and coagulase negative Staphylococci as the most frequently isolated organisms, each representing $20.2 \%$, followed by Pseudomonas aeruginosa $14.6 \%$ and E. coli $10.1 \%$. However, Similar study done in Nepal by Rajbahak et al $(2014)^{29}$ found mostly Pseudomonas aeruginosa ( 45.6\%) followed by Staphylococcus aureus (19.1\%), Acinetobacter spp. $(17.7 \%)$ and coagulase negative Staphylococci (CONS) (5.6\%). Sharma et al (2017) ${ }^{30}$ in their study found the most common isolate was Pseudomonas aeruginosa (38\%), followed by Staphylococcus aureus (35\%), Klebsiella spp.(8\%), Acinetobacter species (5\%), Staphylococcus epidermidis (5\%), Proteus species. (3\%) and E. coli $(1 \%)$. Sewunet et al $(2013)^{31}$ found S.aureus (34.04\%), and P.aeruginosa (31.8\%), were predominant. Datta et $\operatorname{al}(2016)^{32}$ found Pseudomonas aeruginosa (30\%) and Staphylococcus aureus (30\%) as the most common isolate from burn wounds followed by Klebsiella spp. (20\%). In a study done by Ramakrishna et al $(2006)^{33}$ the commonest isolate was Pseudomonas aeruginosa in $41 \%$ followed by Staphylococcus aureus (37\%), Escherichia coli (10\%), Klebsiella spp. $(10 \%)$ and anaerobes in (2\%). Bhat et al (2010) 34 in their study found the commonest organism was $S$. aureus $(27.7 \%)$, followed by $K$ pneumoniae (13.4\%), Proteus mirabilis (12.4\%), Group D streptococcus $(9.4 \%), P$. aeruginosa $(8.9 \%)$ and $E$. coli (6.2\%). Lakshmi et al $(2015)^{35}$ the predominant isolate was Pseudomonas (33.6\%) followed by E.coli (20.9\%), Klebsiella spp. (18.5\%), Proteus spp. (17.3\%), S. aureus (5.7\%) and Acinetobacter spp $(3.9 \%)$. Mundhada et al $(2015)^{25}$ in their study found the most common isolate was Klebsiella pneumoniae (34.40\%) followed by Pseudomonas aeruginosa (23.94\%), Staphylococcus aureus (22.94\%), Escherichia coli (7.34\%), Acinetobacter species $(2.75 \%)$, Proteus mirabilis $(2.75 \%)$, and Citrobacter species. Chamania et al $(2012)^{27}$ in their study found the highest incidence was of Pseudomonas aeruginosa (43\%). As we can see in all the studies Gram negatives were more than Gram positives isolates in burn wound infection. However, the Gram negative organisms were different in different center. From this we can infer that different organism may be common in different centers depending upon this we can know which organism may be suspected if we do not have culture reports.

In our study Acinetobacter spp. was as high as $21 \%$ which is alarming as we can see that none of the centers mentioned above had such high rates of Acinetobacter infection. Acinetobacter is increasingly recognized as a significant healthcareassociated, opportunistic and multidrug-resistant pathogen. ${ }^{36}$ Acquiring multidrug resistant (MDR) Acinetobacter spp infection is associated with an increased risk of patient mortality, and outbreaks have led to the closure of wards. ${ }^{37}$ The appearance of MDR strains of Acinetobacter spp. continues to rise and persists as a complication of burns worldwide. ${ }^{38}$ Currently, carbapenem resistance is one of the leading challenges in managing Acinetobacter healthcare-associated infections. In addition, there are recent reports of outbreaks with pan-drug resistant Acinetobacter baumannii (additional resistance to polymyxin and colistin). ${ }^{39}$ In our study Acinetobacter spp. showed only sensitivity to colistin sulphate $(100 \%)$ and polymyxin B (100\%) and tigecycline $(83.33 \%)$. With meropenem and imipenem it had just 33.33\% sensitivity which is similar to other study by Chandrasekaran et al (2017). ${ }^{40}$ They also did not find Pan resistance to Acinetobacter spp.

In our Study, Pseudomonas spp. showed no sensitivity to cefeperazone+sulbactam and doxycycline. They showed very less sensitivity to amikacin $(50 \%)$, cefepime $(33.33 \%)$, ciprofloxacin $(50 \%)$, gentamicin $(20 \%)$, imipenem $(50 \%)$, levofloxacin (50\%), meropenem $(50 \%)$, piperacillin+tazobactam $\quad(33.33 \%), \quad$ teicoplanin (25\%) and $100 \%$ sensitivity to colsitin sulphate and polymyxin B. In the study done by Ramakrishna et al (2006) ${ }^{33}$ Pseudomonas were found to be highly sensitive to carbapenams followed by aminoglycosides and quinolones. In another study done in Nepal by Rajbahak et al (2014) ${ }^{29}$ they found that antimicrobial sensitivity of $P$. aeruginosa recovered from patient's samples was lower than other isolates. P. aeruginosa was found to be resistant to most of antimicrobials used.

In our study $E$. coli showed no sensitivity to amoxicillin, amoxicillin+clauvanic acid and doxycycline. They showed less sensitivity cefotaxime $(25 \%)$, ceftazidime $(25 \%)$, ceftriaxone $(25 \%)$, gentamicin $(50 \%)$, showed more sensitivity to amikacin (75\%), cefeperazone+sulbactam $(75 \%)$, ciprofloxacin $(75 \%)$, imipenem $(75 \%)$, levofloxacin $(75 \%)$ and meropenem (75\%) and showed $100 \%$ sensitivity to colistin Sulphate, polymyxin B and tigecycline. Similarly results by Al-Ali $(2016)^{28}$ showed E. coli was least resistant to cefepime $(1.1 \%)$, imipenem $1.1 \%$, piperacillin+tazobactam $1.1 \%$, trimethoprim+sulphamethoxazole $22.4 \%$, ceftazidime $15 \%$, ceftriaxone $19 \%$ and amikacin 17 $\%$.

In our study S.aureus were Sensitive to teicloplanin $90 \%$, tetracycline $80 \%$, ceftriaxone 70 
$\%$ and were less sensitive to cloxacillin $50 \%$, amoxicillin and cotrimoxazole $30 \%$.In another study by Bhat and Vasaikar $(2010)^{34}$ most of the $S$. aureus isolates $(99 \%)$ were resistant to penicillin However, all were sensitive to vancomycin and most $(90 \%)$ to fusidic acid. In a similar study done in India by Meheta et al $(2007)^{41} S$. aureus were highly resistant to amoxicillin(69.04\%), erythromycin (75.27\%), and netilmicin (77.75\%).

\section{CONCLUSIONS}

Gram negative were more common isolates from the swab of burn wound. The main organism isolated was Klebsiella spp. Acinetobacter spp were also significantly high and there were many MDR strains hence judicious use of antibiotic for further development of resistant strain in Nepal Cleft and Burn Center, Kirtipur hospital is recommended.

\section{REFERENCES}

1. McManus AT, Mason AD, Jr., McManus WF, Pruitt BA, Jr. A decade of reduced gramnegative infections and mortality associated with improved isolation of burned patients. Arch Surg. 1994;129(12):1306-9.

2. Donati L, Scamazzo F, Gervasoni M, Magliano A, Stankov B, Fraschini F. Infection and antibiotic therapy in 4000 burned patients treated in Milan, Italy, between 1976 and 1988. Burns. 1993;19(4):345-8.

3. Fayazov AD, Shukurov SI, Shukurov BI, Sultanov BC, Namazov AN, Ruzimuratov DA. Disorders of the immune system in severely burned patients. Annals of burns and fire disasters. 2009;22(3):121-30.

4. Lachiewicz AM, Hauck CG, Weber DJ, Cairns BA, van Duin D. Bacterial infections after burn injuries: impact of multidrug resistance. Clinical Infectious Diseases. 2017;65(12):2130 $-6$.

5. O'sullivan $\mathrm{S}, \mathrm{O}$ 'connor $\mathrm{T}$. Immunosuppression following thermal injury: the pathogenesis of immunodysfunction. British journal of plastic surgery. 1997;50(8):615-23.

6. Mooney D, Gamelli R. Sepsis following thermal injury. Comprehensive therapy. 1989;15(9):22.

7. Weinstein RA, Mayhall CG. The epidemiology of burn wound infections: then and now. Clinical Infectious Diseases. 2003;37(4):54350.

8. Punt J, Stranford SA, Jones PP, Owen JA. Kuby immunology. 8 th ed: New York : W.H. Freeman; 2019. 1318 p.

9. Agnihotri N, Gupta V, Joshi RM. Aerobic bacterial isolates from burn wound infections and their antibiograms--a five-year study. Burns. 2004;30(3):241-3.

10. Norbury W, Herndon DN, Tanksley J, Jeschke MG, Finnerty CC. Infection in Burns. Surgical infections. 2016;17(2):250-5.

11. Church D, Elsayed S, Reid O, Winston B, Lindsay R. Burn wound infections. Clinical microbiology reviews. 2006;19(2):403-34.

12. Bollero D, Cortellini M, Stella M, Carnino R, Magliacani G, Iorio M. Pan-antibiotic resistance and nosocomial infection in burn patients: therapeutic choices and medico-legal problems in Italy. Annals of Burns and Fire Disasters. 2003;16(4):182-7.

13. Sewunet T, Demissie Y, Mihret A, Abebe T. Bacterial profile and antimicrobial susceptibility pattern of isolates among burn patients at Yekatit 12 Hospital Burn Center, Addis Ababa, Ethiopia. Ethiopian journal of health sciences. 2013;23(3):209-16.

14. Cuzzell JZ. The Right Way To Culuture a Wound. AJN The American Journal of Nursing. 1993;93(5):48-50.

15. CLSI. Performance standards for antimicrobial susceptibility testing; . 27 ed: Wayne, USA ,Clinical and Laboratory Standards Institute 2017. p. 18-198.

16. Bauer AW, Kirby WM, Sherris JC, Turck M. Antibiotic susceptibility testing by a standardized single disk method. American journal of clinical pathology. 1966;45(4):4936.

17. Commission BP. British Pharmacopeia 2018. TSO: London, UK. 2018;3.

18. CLSI. Statistical Quality Control for Quantitative Measurement Procedures: Principles and Definitions. Wyane USA ,Clinical and Laboratory Standards Institute 2017; 2017. p. 1-61.

19. Mackie TJ. Mackie \& McCartney practical medical microbiology: Harcourt Health Sciences; 1996.

20. Paudel PDB. Pattern of Burn patients admitted in a Burn Unit of Bir Hospital Kathmandu. Post-Graduate Medical Journal of NAMS. 2010;10(02).

21. Peden M, McGee K, G. S. The Injury Chartbook: A graphical overview of the global burden of injuries 2002. Available from http:// www.who.int/violence_injury_prevention/ publications/other_injury/chartb/en/

22. Smolle C, Cambiaso-Daniel J, Forbes AA, Wurzer P, Hundeshagen G, Branski LK, et al. Recent trends in burn epidemiology worldwide: A systematic review. Burns. 2017;43(2):249-57.

23. Karki B, Rai SM, Nakarmi KK, Basnet SJ, Magar MG, Nagarkoti KK, et al. Clinical Epidemiology of Acute Burn Injuries at Nepal Cleft and Burn Centre, Kathmandu, Nepal. Ann Plast Surg. 2018;80(3 Suppl 2):S95-s7. 
24. Rai SM, Karki B, Nakarmi K, Ghartimagar M, Nagarkoti K, Joshi KD, et al. Retrospective study on early outcome of acute burn injuries treated at Nepal Cleft and Burn Centre of Public Health Concern Trust-Nepal. Journal of Nepal Health Research Council. 2014;12 (28):195-9.

25. Mundhada $\mathrm{S}$, Waghmare $\mathrm{P}$, Rathod $\mathrm{P}$, Ingole $\mathrm{K}$. Bacterial and fungal profile of burn wound infections in Tertiary Care Center. Indian Journal of Burns. 2015;23(1):71-5.

26. Aljanaby A, Abduljabbar Jaloob Aljanaby I. Prevalence of aerobic pathogenic bacteria isolated from patients with burn infection and their antimicrobial susceptibility patterns in $\mathrm{Al}$ -Najaf City, Iraq- a three-year cross-sectional study. F1000Research. 2018;7:1157.

27. Chamania S, Hemvani N, Joshi S. Burn wound infection: Current problem and unmet needs. Indian Journal of Burns. 2012;20:18.

28. Al-Aali K. Microbial profile of burn wound infections in burn patients, Taif, Saudi Arabia. Arch Clin Microbiol. 2016;7(2):1-9.

29. Rajbahak S, Shrestha C, Singh A. Bacteriological changes of burn wounds with time and their antibiogram. Scientific World. 2014;12(12):70-6.

30. Sharma L, Srivastava H, Pipal DK, Dhawan R, Purohit PM, Bhargava A. Bacteriological profile of burn patients and antimicrobial susceptibility pattern of burn wound isolates. International Surgery Journal. 2017;4(3):101923.

31. Sewunet T, Demissie Y, Mihret A, Abebe T. Bacterial profile and antimicrobial susceptibility pattern of isolates among burn patients at Yekatit 12 hospital burn center, Addis Ababa, Ethiopia. Ethiopian journal of health sciences. 2013;23(3):209-16.

32. Datta S, Ghosh T, Sarkar D, Tudu NK, Chatterjee TK, Jana A. Bacteriological Profile of Burn Wounds and Their Antibiotic Susceptibility Pattern in a Tertiary Care Hospital. International Journal of Scientific Study. 2016;4(5):141-5.
33. Ramakrishnan MK, Sankar J, Venkatraman J, Ramesh J. Infections in burn patientsexperience in a tertiary care hospital. Burns. 2006;32(5):594-6.

34. Bhat V, Vasaikar S. Bacteriological profile and antibiogram of aerobic burn wound isolates in Mthatha, Eastern Cape, South Africa. Southern African Journal of Epidemiology and Infection. 2010;25(4):169.

35. Lakshmi N, Ramalakshni K, Perala K, Jayalaxmi M. Bacteriological profile and antibiogram of burn wound infections in a tertiary care hospital. Journal of Dental and Medical Sciences. 2015;14(10):1-4.

36. Peleg AY, Seifert H, Paterson DL. Acinetobacter baumannii: emergence of a successful pathogen. Clinical microbiology reviews. 2008;21(3):538-82.

37. Sherertz RJ, Sullivan ML. An outbreak of infections with Acinetobacter calcoaceticus in burn patients: contamination of patients' mattresses. The Journal of infectious diseases. 1985;151(2):252-8.

38. Abbott I, Cerqueira GM, Bhuiyan S, Peleg AY. Carbapenem resistance in Acinetobacter baumannii: laboratory challenges, mechanistic insights and therapeutic strategies. Expert review of anti-infective therapy. 2013;11(4):395-409.

39. Van Looveren M, Goossens H. Antimicrobial resistance of Acinetobacter spp. in Europe. Clinical microbiology and infection : the official publication of the European Society of Clinical Microbiology and Infectious Diseases. 2004;10(8):684704.

40. Chandrasekaran S, Alagirisamy R, Jayaraman S, Jagannathan M. Resistant Acinetobacter: A Booming Peril. Indian Journal of Burns. 2017;25(1):67-71.

41. Mehta M, Dutta P, Gupta V. Bacterial isolates from burn wound infections and their antibiograms: A eight-year study. Indian Journal of Plastic Surgery. 2007;40.

Citation: Lamichhane A, Nakarmi KK, Dahal P, Basnet SJ, Pokharel PB, Bhattarai S, Rai SM. Bacteriological Profile of Burn Patients and Antimicrobial Susceptibility Pattern of their Wound Isolates at Nepal Cleft and Burn Center. JCMS Nepal. 2019; 15(3):160-6. 